\title{
FT-IR Spectroscopy Applied for Surface Clays Characterization
}

\section{Paul Djomgoue ${ }^{\#}$, Daniel Njopwouo}

Laboratoire de Physico-Chimie des Matériaux Minéraux, Département de Chimie Inorganique, Université de Yaoundé I, Yaoundé I, Cameroun.

Email: djomgouep@gmail.com

Received May $8^{\text {th }}, 2013$; revised June $11^{\text {th }}, 2013$; accepted July $10^{\text {th }}, 2013$

Copyright (C) 2013 Paul Djomgoue, Daniel Njopwouo. This is an open access article distributed under the Creative Commons Attribution License, which permits unrestricted use, distribution, and reproduction in any medium, provided the original work is properly cited.

\begin{abstract}
The present paper should be considered as a review of the application of Fourier Transform Infra-Red for surface clay characterization. The application of surface clay materials for water treatment, oil adsorption, excipients or as active in drugs has largely increased these recent years. The surface clay material presents hydroxyl groups, which can link very easily water molecules. These hydroxyl groups can react with organic groups and by their vibration in the infra-red region, FT-IR can be easily used as a technical method for surface clay characterization. In this paper, we focus on the determination of Lewis and Brönsted acid sites on the clay surface, a critical review of the sample preparation, the surface characterization of bulk clay and the modified surface clay samples using FT-IR spectroscopy.
\end{abstract}

Keywords: Clay Materials; Surface Clays; Hydroxyls; Surface Acidity; IR Spectroscopy

\section{Introduction}

Clay minerals are a well-known class of natural inorganic materials with well-known structural adsorption, rheological and thermal properties. These materials originally have a hydrophilic character due to the presence of the surface hydroxyl $(-\mathrm{OH})$ groups, which can link very easily water molecules [1].

For many years, the clay materials have been used for adsorption of heavy metals [2,3], dye molecules [4], herbicides [5,6], anions such as nitrates [7], like phosphates and sulphates, or gas adsorption [8], like $\mathrm{SO}_{2}$.

In industry, these materials are also used as a catalysator in organic syntheses or as excipient in pharmacy. The application of clay materials is greatly governed by their surface properties like adsorption capacities, surface charges, large surface area, charge density, the type of exchangeable cations, hydroxyl groups on the edges, silanol groups of the crystalline defects or broken surfaces and Lewis and Brönsted acidity [9]. Phyllosilicate surfaces contain two basic types, i.e., siloxane surface and hydroxyl surface. The 2:1 clay minerals (e.g., smectite group minerals) only contain siloxane surfaces while the 1:1

\footnotetext{
*Review article.

${ }^{\#}$ Corresponding author.
}

clay minerals (e.g., kaolinite group minerals) contain both the two kinds of surfaces (Figures 1 and 2).

The hydroxyl surfaces (e.g., Al-octahedral surface in kaolinite) are excellent sites for grafting since the surface hydroxyls can condensate with alkoxyl groups and/or the

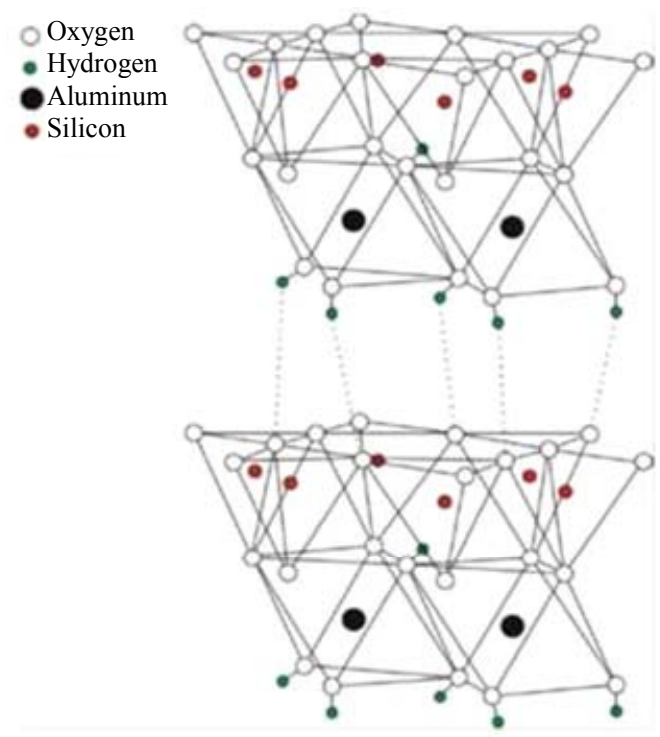

Figure 1. Structure of 1:1 clay mineral [10]. 


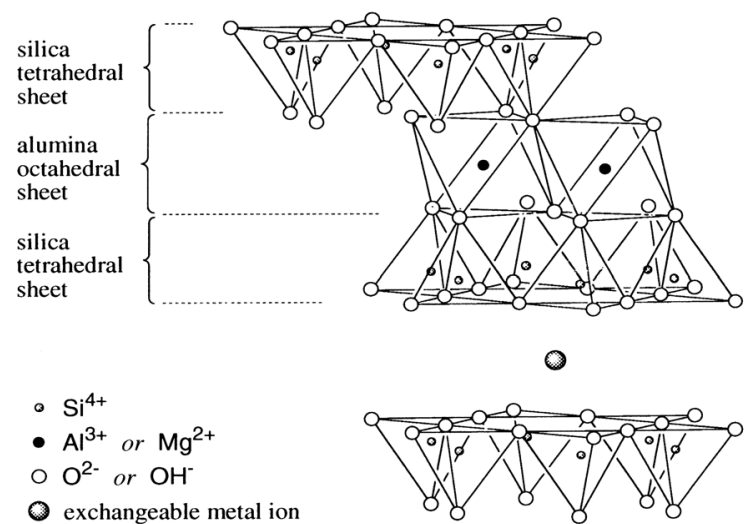

Figure 2. Structure of 2:1 clay mineral [11].

hydroxyls in the hydrolyzed silane. Due to the high ratio of the terminal surface area of the basal surface area, hydroxyl groups located at breaking edges play an important role in the silane grafting reaction. However, due to the variation of the structure and property of phyllosilicates, prominent differences of the grafting mechanism and grafting sites exist among different clay minerals. For swelling clay minerals such as montmorillonite, silane is readily intercalated into the interlayer space [12]. Chemical modifications on the surface of clay with acids, bases, cationic surfactants and certain polyhydroxyl cations were also conducted to improve their sorption capacity. Surface modification of clay minerals has attracted much attention because they obtained products exhibiting properties suitable for many applications in material science [12] and environmental engineering [13].

Several characterization techniques were employed in order to identify the changes in clay: fourier transforminfra-red (FT-IR), X-ray diffraction (XRD), raman spectroscopy, $\mathrm{Si} / \mathrm{Al}$ NMR, transmission electron microscopy (TEM), scanning electron microscopy (SEM), energy dispersive X-ray spectroscopy (EDX) and nitrogen adsorption-desorption isotherms [14]. FT-IR is a complementary method to X-ray diffraction (XRD) and other methods used to investigate clays and clay minerals. FT-IR is rapid, inexpensive and can be available in many laboratories. For the FT-IR spectroscopy, it is still a discussion about the technique procedure, the nature of bound between the clay surface and the organic molecule after adsorption or grafting. In this paper, we intend to give some recommendations for these questions.

The study presented in this paper is a review aimed at utilization of FT-IR spectroscopic as the surface clay method characterization of bulk materials or modified clay samples, determination of Lewis and Brönsted acid sites on clay surface, and a critical review of the sample preparation.

\section{Techniques}

Today, infrared studies of the adsorption properties of clay surfaces may be limited by sample preparation and handling problems. IR absorption spectra of clay minerals are usually obtained from self-supporting films, films sedimented on IR-transparent windows, alkali-halide disks (e.g. $\mathrm{KBr}$ ), or from oil mulls (the most common mulling agent is Nujol-paraffin oil).

Transmission spectroscopy is the oldest and most commonly used method in the clay mineral studies. Naturally occurring clay minerals are powders or solids that can be ground into powders. The $\mathrm{KBr}$ pressed disc technique is frequently used to prepare samples for IR analysis. Convenient means to prepare a clay sample for FTIR spectroscopic analysis is to mix the clay sample with potassium bromide $(\mathrm{KBr})$ and place the $\mathrm{KBr}$ /clay mixture into a dye under pressure to form a pellet. In order to minimize the amount of the adsorbed water, the discs should be heated in a furnace overnight at $130^{\circ} \mathrm{C}$ [15]. In our laboratory, after heated at $130^{\circ} \mathrm{C}$, the sample should be immediately submitted for FTIR measurement to avoid atmospheric water adsorption. The pressing of $\mathrm{KBr}$ with clay to prepare the $\mathrm{KBr}$ pellet may alter the spectrum through the exchange of $\mathrm{K}$ into the structure. The danger occurs in the stage of mixing the kaolinite with $\mathrm{KBr}$ before the mixture is pressed into a disk [15]. If that mixing is gentle it causes no effect, but if grinding is used in the mixing, severe changes in the intensities of some of the absorption bands occur due to an interaction between the $\mathrm{KBr}$ and the kaolinite. Bell et al. [16] show that the magnitude of change depends on the absolute pressure, the pressing time and whether a salt matrix is used. Pressing with $\mathrm{KBr}$ causes larger differences than pressing neat. This simple experiment shows that IR hydroxyl peaks change irreversibly when kaolinite powder is pressed into pellets. This may be due to optical or chemical effects. According to these authors, due to the hydroxyl intensity changes, the valuable structural information is lost when kaolinite IR spectra are acquired using pressed $\mathrm{KBr}$ pellets [16].

The self-supporting film (SSF) is another technique for preparation of samples for FTIR measurement. In this technique, a drop of that aqueous clay suspension is pipetted onto a thin polyethylene sheet and allowed to evaporate to dryness overnight at room temperature. But, the problem with this technique is for smectite clay materials. The important property of smectites is their swelling ability, when exposed to humidity, these minerals swell in a series of steps as water enters the interlayer region to form so-called one-, two- and three-layer hydrates. In studies of smectite dehydration SSF technique is more suitable because it allows examination of a sample without a $\mathrm{KBr}$ matrix, known to be hygroscopic [17]. In other points, absorption bands of water molecules adsorbed on $\mathrm{KBr}$ and those present in the smectite overlap are not possible to distinguish. Therefore it is good to heat the 
sample before measuring, Madejova et al. [17] threat for $15 \mathrm{~min}$ at $150^{\circ} \mathrm{C}$ a Montmorillonite for film Self-supporting film. Figure 3 presents the result of heated and unheated samples. We can see a completely eliminated band near $3400 \mathrm{~cm}^{-1}$ related to $\mathrm{H}_{2} \mathrm{O}$ adsorbed on the sample, and a well-resolved band at $3629 \mathrm{~cm}^{-1}$ assigned to $\mathrm{OH}^{-}$ stretching vibrations of structural hydroxyls remained. This technique was also useful for the $950-800 \mathrm{~cm}^{-1}$ region, where well-resolved absorption bands are present.

Another method to obtain IR spectra of solids are Nujol (mineral oil) mulls between $\mathrm{KBr}$ plates. Good results are obtained by this method only if the average particle size of the solid is somewhat less than the wavelength of light the particles are to transmit. The sample should be grounded in a mortar to reduce the average particle size to $1-2 \mu \mathrm{m}$. About 5 to $10 \mathrm{mg}$ of finely ground sample are then placed onto the face of a $\mathrm{KBr}$ plate, a small drop of mineral oil is added and the second window is placed on top. With a gentle circular and back-and-forth rubbing motion of the two windows, evenly distribute the mixture between the plates [18].

The mixture should appear slightly translucent, with no bubbles, when properly prepared. The FT-IR using from oil mulls or Nujol technique modified of the spectra of some organo-clays may occur in alkali halide disks because they may react either with the clay (e.g. cation exchange with the alkali halides, intercalation of the alkali halides, grinding or pressure effects) or with the organic matter (e.g. extracting the organic matter from the clay by Nujol, replacing of adsorbed organic matter by alkali halide) [19].

Attenuated Total Reflection FTIR (ATR-FTIR) is also an alternative method for FT-IR sample preparation where raw material is placed directly onto the diamond crystal for data acquisition [20]. One advantage of ATRIR over transmission-IR, is the limited path length into

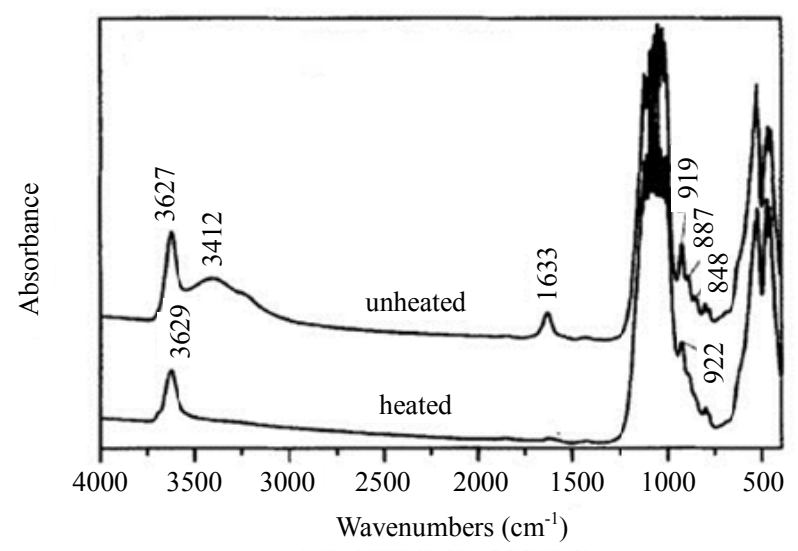

Figure 3. Transmission IR spectra of SWy-2 (montmorillonite) self-supporting film-sampling techniques; slight heating [17]. the sample. This avoids the problem of strong attenuation of the IR signal in highly absorbing media, such as aqueous solutions. During preparation, powdered core samples were settled $(<2 \mu \mathrm{m}$ grain size fraction), dried and heated up at $80^{\circ} \mathrm{C}$ to minimize the adsorbed water content and then kept in closed vessels covered by parafilm before ATR-FTIR measurements [21].

\section{Clay Surface Characterizations}

\subsection{Characterization of the Hydroxyls at the Surface Clays}

The triclinic layer structure of pure kaolinite reveals four well resolved $(-\mathrm{OH})$ bands in IR spectrum. Three of these bands are assigned to the stretching vibrations of surface hydroxyl groups $\left(3652,3671\right.$, and $\left.3694 \mathrm{~cm}^{-1}\right)$ while the fourth $\left(3620 \mathrm{~cm}^{-1}\right)$ is attributed to the vibrations of inner hydroxyl groups. The $\mathrm{OH}-$ bending region of kaolinite shows vibrations of the inner surface $\mathrm{OH}$ groups at 913 $\mathrm{cm}^{-1}$ and that of surface $\mathrm{OH}$ groups near $936 \mathrm{~cm}^{-1}$; additional bands near 701 and $755 \mathrm{~cm}^{-1}$ are associated with the surface hydroxyls. Bands due to $v(\mathrm{AlFeOH})$ at $865-$ $875 \mathrm{~cm}^{-1}$ and stretching at $3607 \mathrm{~cm}^{-1}$ are typical of $\mathrm{Fe}$ bearing kaolinites [22]. The four $\mathrm{OH}$-stretching bands in the infrared spectrum of kaolinite are widely used in the study of adsorption and interface reactions of this mineral. Raman spectra of kaolinites exhibit five OH-stretching bands, the additional Raman feature at $\sim 3685 \mathrm{~cm}^{-1}$ being located between bands at about 3696 and 3670 $\mathrm{cm}^{-1}$.

For the halloysite compared with kaolinite, two infrared bands are observed at 1648 and $1629 \mathrm{~cm}^{-1}$ in the halloysite spectrum. The assignment of these latter two bands is to the water $\mathrm{HOH}$ bending mode. The fact that two bands are observed suggests that there is water present in the halloysite (10 $\AA$ ) structure. This corresponds with the hydroxyl stretching wavenumbers above. The band at $1648 \mathrm{~cm}^{-1}$ corresponds to strongly hydrogen bonded water, whereas the band at $1629 \mathrm{~cm}^{-1}$ is attributed to less strongly hydrogen bonded water and corresponds to the position of the water bending mode of liquid water [23].

The structural $\mathrm{OH}^{-}$bending mode in montmorillonite absorbs between 700 and $950 \mathrm{~cm}^{-1}$ and shows a series of discrete peaks that indicates the cation composition in the octahedral sheet. The $\mathrm{OH}^{-}$bending mode of the $\mathrm{Al}_{2} \mathrm{OH}$ group absorbs near $920 \mathrm{~cm}^{-1}$; The $\mathrm{OH}^{-}$of $\mathrm{Fe}(\mathrm{III}) \mathrm{AlOH}$ absorbs near $890 \mathrm{~cm}^{-1}$; the $\mathrm{OH}^{-} \mathrm{MgAlOH}$ absorbs near $840 \mathrm{~cm}^{-1}$; and The $\mathrm{OH}^{-} \mathrm{Fe}(\mathrm{II}) \mathrm{Fe}(\mathrm{III}) \mathrm{OH}$ absorbs near 800 $\mathrm{cm}^{-1}$ [24]. The region above $3000 \mathrm{~cm}^{-1}$ wavenumber of FT-IR contains information about the silanols of montmorillonite. The characteristic vibration peaks of smectite are at $3628 \mathrm{~cm}^{-1}(\mathrm{O}-\mathrm{H}$ stretching $)$ [25]. 


\subsection{Characterization of Modified Clay Surface Samples}

Murakami et al. [26] modified a kaolinite with butanediols. The IR spectrum of Kao-1,2BD (kaolinite modified with 1,2-Butanediols) showed the bands at 2970, $2941 \mathrm{~cm}^{-1}\left(\mathrm{rasCH}_{2}\right)$ and $2885 \mathrm{~cm}^{-1}\left(\mathrm{rsCH}_{2}\right)$, indicating the presence of the organic component (Figure 4(d)). The spectrum of Kao-1,3BD (kaolinite modified with 1,3Butanediols) also showed a pattern similar to that of Kao-1.2BD (kaolinite modified with 1,2-Butadiols); the bands at $2971,2931 \mathrm{~cm}^{-1}(\mathrm{rsCH} 2)$ and $2856 \mathrm{~cm}^{-1}\left(\mathrm{rsCH}_{2}\right)$ were observed (Figure 4(d)). The spectrum of methoxymodified kaolinite (Figure 4(b)) shows the disappearance of the bands at 3668 and $3653 \mathrm{~cm}^{-1}$ and the appearance of the bands at 3645 and $3631 \mathrm{~cm}^{-1}$. The shifts are ascribable to the variation in the interlayer environments of the hydroxyl groups. The broad band centered at $3550 \mathrm{~cm}^{-1}$ can be due to $\mathrm{OH}$ of the interlayer water. The bands at 3645 and $3631 \mathrm{~cm}^{-1}$ found for methoxymodified kaolinite disappeared in the spectrum of Kao1,2BD (kaolinite modified with 1,2-Butanediols), and a new band at $3599 \mathrm{~cm}^{-1}$ was observed (Figure 4(c)). The band is ascribable to $\mathrm{OH}$ of hydroxyl groups on the interlayer surface hydrogen bonded with grafted 1,2-Butanediols. A broad band at $3550 \mathrm{~cm}^{-1}$ due to $\mathrm{rOH}$ of interlayer water was also observed. In the spectrum of Kao-1,3BD, the bands at 3645 and $3631 \mathrm{~cm}^{-1}$ observed in the spectrum of methoxy-modified client disappeared and a new broadband at $3650 \mathrm{~cm}^{-1}$ and a sharp band at $3599 \mathrm{~cm}^{-1}$ were observed (Figure 4(d)) [26].

Priyanthi et al. [27] show that infrared spectroscopy is a powerful method for monitoring and analyzing clayfluid interactions. They studied the characteristic of IR bands, such as $\mathrm{Si}-\mathrm{O}$ stretching, $\mathrm{O}-\mathrm{H}$ stretching of structural $\mathrm{O}-\mathrm{H}$ group, $\mathrm{O}-\mathrm{H}$ stretching and $\mathrm{H}-\mathrm{O}-\mathrm{H}$ bending

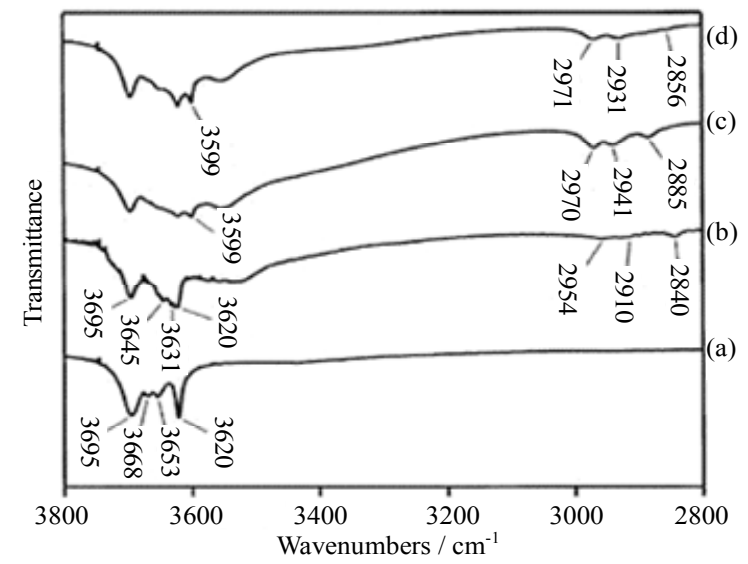

Figure 4. Infrared spectra of (a) kaolinite, (b) dry methoxy-modified kaolinite, (c) Kao-1,2BD, and (d) Kao-13,BD [26]. of interlayer water, in clay, and characteristic IR vibration bands such as $\mathrm{C}=\mathrm{O}$ and $\mathrm{C}-\mathrm{C}-\mathrm{O}$ stretching bands in solvents, they use these results to understand the clayfluid interactions at the molecular level. Important is to dry the clay sample in order to remove water before FTIR measurements, however, slight changes in structure during manipulation cannot be ruled out and the results could be wrongly interpreted. We suggest many other techniques in order to compare the results like powder X-ray diffraction.

\subsection{Determination of Brönsted and Lewis Acid Sites}

There are several methods to determine the surface acidity of clay minerals such as Hammett indicator technique, $n$-butylamine back titration, microcalorimetry and FT-IR spectroscopy of adsorbed basic probe molecules [28]. Brönsted and Lewis acid sites can be distinguished from the IR spectrum of pyridine adsorbed on the clay surface. Brönsted and Lewis acid site concentrations are calculated using the IR bands centered at $1545 \mathrm{~cm}^{-1}$ (characteristic of the pyridium ions $\mathrm{pyH}^{+}$) and $1455 \mathrm{~cm}^{-1}$ (characteristic of the pyL species), respectively, using the following formula:

$$
\begin{aligned}
& \mathrm{C}_{\text {Lewis }}=\mathrm{A}_{1} \mathrm{~S} * 1000 / \varepsilon_{1} \omega \\
& \mathrm{C}_{\text {Bronsted }}=\mathrm{A}_{\mathrm{b}} \mathrm{S} * 1000 / \varepsilon_{\mathrm{b}} \omega
\end{aligned}
$$

where $A_{l}$ is the area of the IR band centered at $1450 \mathrm{~cm}^{-1}$, $A_{b}$ is the area of the IR band centered at $1545 \mathrm{~cm}^{-1}, S$ is the area of the pellet $\left(\mathrm{cm}^{2}\right), \omega$ is the weight of the pellet

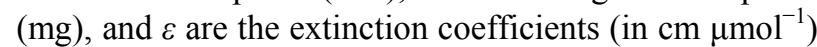
$\varepsilon_{l}=1.28 \mathrm{~cm} \mathrm{\mu mol}^{-1}, \varepsilon_{\mathrm{b}}=1.13 \mathrm{~cm} \mathrm{\mu mol}^{-1}$ [28].

The infrared absorption bands in the $1400-1700 \mathrm{~cm}^{-1}$ region for pyridine adsorbed on silica-alumina and aluminosilicates have been used to study their acidity since the 1960s [2]. But it is still a problem. It is known that spectra of MMT before pyridine adsorption contain in this region only one band near $1630 \mathrm{~cm}^{-1}$ due to the bending $\mathrm{OH}$ vibrations of water molecules; therefore it important to dry the sample before the pyridine adsorption [28].

The Brönsted sites (B) show bands near 1490, 1540, and $1635 \mathrm{~cm}^{-1}$. The $1540 \mathrm{~cm}^{-1}$ band is typical of this site; the corresponding species is the pyridinium ion $\left(\mathrm{PyH}^{+}\right)$. It is assumed that tricoordinated aluminum atoms with an electron-free orbit constitute Lewis acid centers (L). Pyridine coordinated to the Lewis sites absorbs near 1455, 1490 , and $1610-1625 \mathrm{~cm}^{-1}$; the $1455 \mathrm{~cm}^{-1}$ band is typical of these sites. The third type of site, corresponding to hydrogen-bonded pyridine $(\mathrm{H})$ on the clay solid, has vibrations near 1440 and $1590 \mathrm{~cm}^{-1}$ (Figure 5) [28]. These bands are probably due to a strong interaction between the cation and the pyridine molecule, by attraction of the cation into the electrostatic field [17]. 


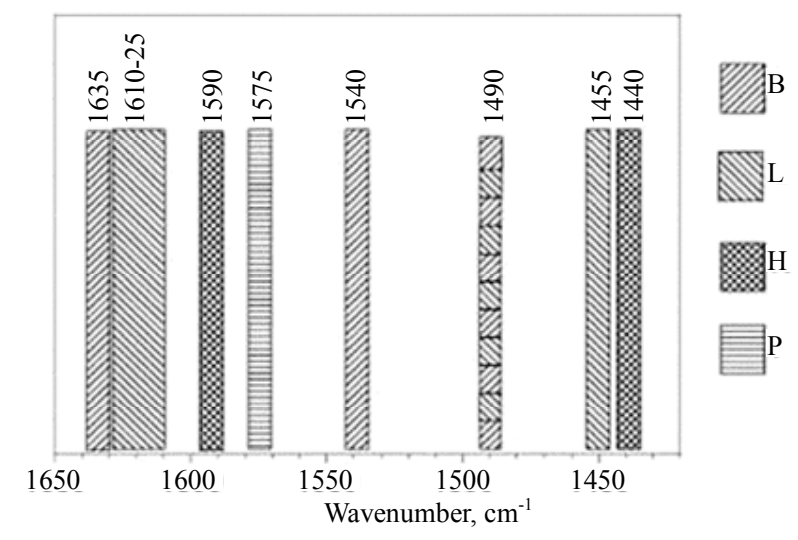

Figure 5. Bands in the IR spectra of acid solids with adsorbed pyridine in the $1420-1650 \mathrm{~cm}^{-1}$ region. Pyridine adsorbed on B, Brönsted sites; $L$, Lewis sites; $H$, hydrogenbonded, and $P$, physisorbed pyridine [28].

The band at $3620 \mathrm{~cm}^{-1}$ corresponds to the "inner hydroxyls" located on the plane, common to octahedral and tetahedral sheets, as described previously. Bands recorded at 3668 and $3652 \mathrm{~cm}^{-1}$ are suggested could be attributed to the vibration of the "outer hydroxyls" located at the surface and along broken edges of kaolinite monocrystals [17].

\subsection{Clay Surface Complexation}

Adsorption of metal ions from aqueous solution on oxides, clay minerals and clays has been a subject of interest in chemistry as well as in other research areas. It is considered that the adsorption of heavy metal ions and complexes on clay minerals occurs as a result of ion exchange, surface complexation, hydrophobic interaction, and electrostatic interaction [9]. The adsorption modes of ions on mineral surfaces are mainly divided into outersphere and inner-sphere surface complexes. In general, the chemical interactions in inner-sphere complexes are stronger than those of outer-sphere complexes (Figure 6) [9]. These differences in binding strengths influence the mobility of ionic species in the environment. Hence, a distinction between outer-sphere and inner-sphere complexes is significant and FT-IR is helpful for the evaluation of the outer-sphere and inner-sphere surface complexes. The evaluation of outer-sphere and inner-sphere surface complexes needs techniques such as attenuated total internal reflection spectroscopy (ATR-FTIR). Zhang et al. [29] studied the Cd(II)-sulfate interactions on the goethite-water interface, ATR-FTIR studies indicated that sulfate adsorption on goethite occurred via both outerand inner-sphere complexation; the authors assign peaks at 1170,1132 , and $1050 \mathrm{~cm}^{-1}$ to inner-sphere species. More recently Brechbühl et al. [30] studied the compettive sorption of carbonate and arsenic to hematite: combined ATR-FTIR and batch experiments, the ATR-FTIR spectra indicated the predominant formation of bidentate binuclear inner-sphere surface complexes for both sorbed arsenate and sorbed carbonate.

Moreover, the FT-IR could be used to show the bound between the clay and the metal ion after adsorption, for example, Eren et al. [13] modified a bentonite clay using $\mathrm{MnCl}_{2}$ for copper adsorption, the FT-IR of the sample after copper adsorption presented in Figure 7 shows that the stretching $\mathrm{OH}$ band was shifted up to $3668 \mathrm{~cm}^{-1}$ and, moreover, new bands appeared near 3591 and $3460 \mathrm{~cm}^{-1}$ in the spectrum of MMB-Cu(II) sample. The IR spectrum of the $\mathrm{MMB}-\mathrm{Cu}(\mathrm{II})$ sample showed a strong band of water near $3400 \mathrm{~cm}^{-1}$, due to the overlapping asymmetric $v_{3}$ and symmetric $v_{1}(\mathrm{H}-\mathrm{O}-\mathrm{H})$ stretching vibrations. We are also modified the magnetite clay with Black Eriochrome T, NET and the FTIR spectroscopy help us to show the modification of our sample using $\mathrm{KBr}$ technique [4].

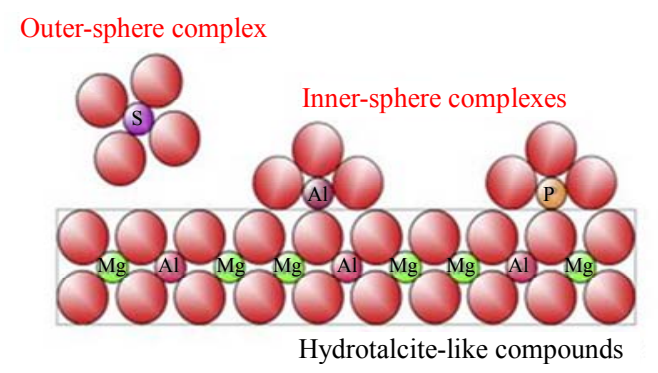

Figure 6. Outer-sphere and inner-sphere surface complexes at the hydrotalcite-like compounds [31].

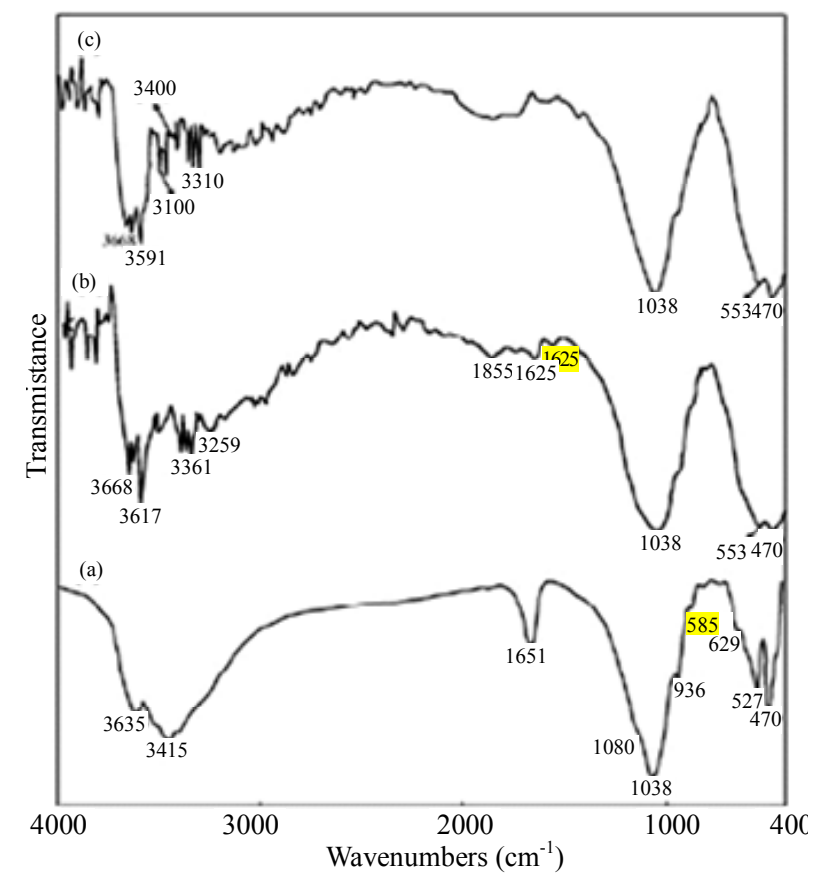

Figure 7. IR spectra of the RB (a) bulk samples, MMB (b) modified with $\mathrm{MnCl}_{2}$, and $\mathrm{MMB}-\mathrm{Cu}(\mathrm{II})$ (c) [13]. 
Nicolini et al. [32] studied the dehydrated halloysite intercalated mechanochemically with urea: Thermal behavior and structural aspects; the absorption bands at 3696 and $3622 \mathrm{~cm}^{-1}$ in the FTIR spectrum were assigned to the stretching vibration due to external and internal $\mathrm{O}-\mathrm{H}$ groups of halloysite, respectively. The intensity of the band at $3696 \mathrm{~cm}^{-1}$ is lower than the band at 3622 $\mathrm{cm}^{-1}$, because it is mainly the external hydroxyl groups that are responsible for the interactions with urea through $\mathrm{N}-\mathrm{H}$ groups and new bands were observed at 3503 and $3390 \mathrm{~cm}^{-1}$ indicated the adsorption of urea.

Table 1 gives the wave number values of the hydroxyls group of the most used clay minerals like kaolinite, halloysite and montmorillonite. It appears in this table that these values are between $3000-3800 \mathrm{~cm}^{-1}$ and these values are really close, most are around $3600 \mathrm{~cm}^{-1}$. It's not sufficient to use only FTIR to characterize clay minerals, other methods like powder X-ray, thermal gravimetric etc. should be combined to have a complete characterization.

\section{Conclusion}

The present review was aimed to the technical procedural methods used by FT-IR for clay surface characterization because, FT-IR remain is an economical, rapid and common technique. A spectrum can be obtained in a few minutes and the instruments are sufficiently inexpensive as to be available in many laboratories.

An IR spectrum can serve as a fingerprint for mineral identification, but it can also give unique information

Table 1. Wavenumber peaks of the hydroxyl, OH group of most used clays.

\begin{tabular}{|c|c|c|}
\hline Clay minerals & Wavenumber $(\mathrm{OH}) \mathrm{cm}^{-1}$ & Refs \\
\hline Kaolinite & $3696,3671,3650$ & {$[33]$} \\
\hline Halloysite & 3696 (OH-internal), 3622 (OH-external) & {$[32]$} \\
\hline Montnorillonite & 3624 (Al-OH), 3422 (Water) & {$[34]$} \\
\hline Verniculite & $\begin{array}{l}3675 \text { (Mg-vermiculite), } \\
3594 \text { (Na-vermiculite) }\end{array}$ & {$[35]$} \\
\hline Bentonite & 3625 & {$[15]$} \\
\hline Illite & 3600 & {$[36]$} \\
\hline Chlorite & 3670,3580 (Interlayer) 3440 (water) & {$[37]$} \\
\hline Smectite & 3622 & {$[38]$} \\
\hline saponite & $3740(\mathrm{Si}-\mathrm{OH}), 3670\left(\mathrm{Mg}(\mathrm{OH})_{2}\right), 3570$ & [39] \\
\hline Sepiolite & $3719(\mathrm{Si}-\mathrm{OH}) 3689\left(\mathrm{Mg}_{3} \mathrm{OH}\right)$ & {$[40]$} \\
\hline Nacrite & $\begin{array}{l}3701 \text { and } 3647 \text { (out-of-plane), } \\
3647 \text { (in-plane) }\end{array}$ & {$[23]$} \\
\hline Dickite & $3708,3654,36228($ Inner surface $\mathrm{OH})$ & {$[41]$} \\
\hline Lizardite & $3686(\mathrm{Mg}-\mathrm{OH})$ & {$[42]$} \\
\hline
\end{tabular}

about the mineral structure, including the family of minerals to which the specimen belongs, the degree of regularity within the structure, the nature of isomorphic substituents, the distinction of molecular water from constitutional hydroxyl, and the presence of both crystalline and non-crystalline impurities [17].

Among different techniques samples preparing for IR measurement are self-supporting films, films sediment on IR-transparent windows, alkali-halide disks like: $\mathrm{KBr}$, $\mathrm{NaCl}$ etc., or from oil mulls. Many parameters influence the results in each case as the pressing, grinding effect and atmospheric water adsorption, therefore the choose of preparing samples should be greatly depending on the type of clay and the results we need to show. As a recommendation for using FT-IR for the surface clay characterization, the Attenuated Total Reflection, the ART-FTIR method, could be a best technique for the sample preparation. It is important to dry the sample up to $100^{\circ} \mathrm{C}$ to eliminate the adsorbed water on clay sample and this gives a good result and interpretation in the range 3000 $4000 \mathrm{~cm}^{-1}$ where appear the surface hydroxyl bands of clays.

\section{Acknowledgements}

The authors thank the anonymous reviewers for their insightful suggestions to improving the initial manuscript.

\section{REFERENCES}

[1] D. W. Cho, C. M. Chon, Y. Kim, B.-H. Jeon, F. W. Schwartz, E.-S. Lee, et al., "Adsorption of Nitrate and $\mathrm{Cr}(\mathrm{VI})$ by Cationic Polymer-Modified Granular Activated Carbon," Chemical Engineering Journal, Vol. 175, 2011, pp. 298-305. http://dx.doi.org/10.1016/j.cej.2011.09.108

[2] K. O. Adebowale, E. I. Unuabonaha and B. I. Olu-Owolabi, "Kinetic and Thermodynamic Aspects of the Adsorption of $\mathrm{Pb} 2+$ and $\mathrm{Cd}^{2+}$ Ions on Tripolyphosphate-Modified Kaolinite Clay," Chemical Engineering Journal, Vol. 136, No. 2-3, 2008, pp. 99-107. http://dx.doi.org/10.1016/j.cej.2007.03.012

[3] J. Hizal and R. Apak, "Modeling of Cadmium(II) Adsorption on Kaolinite-Based Clays in the Absence and Presence of Humic Acid," Applied Clay Science, Vol. 32, No. 3-4, 2006, pp. 232-244. http://dx.doi.org/10.1016/j.clay.2006.02.002

[4] P. Djomgoue, M. Siewe, E. Djoufac, P. Kenfack and D. Njopwouo, "Surface Modification of Cameroonian Magnetite Rich Clay with Eriochrome Black T. Application for Adsorption of Nickel in Aqueous Solution," Applied Surface Science, Vol. 258, No. 19, 2012, pp. 7470-7479. http://dx.doi.org/10.1016/i.apsusc.2012.04.065

[5] J. L. Marco-Brown, C. M. Barbosa-Lema, R. M. Torres Sánchez, R. C. Mercader and M. dos Santos Afonso, "Adsorption of Picloram Herbicide on Iron Oxide Pillared Montmorillonite," Applied Clay Science, Vol. 58, 2012, pp. 25-33. http://dx.doi.org/10.1016/j.clay.2012.01.004 
[6] M. S. El-Geundi, M. M. Nassar, T. E. Farrag and M. H. Ahmed, "Removal of an Insecticide (methomyl) from Aqueous Solutions Using Natural Clay," Alexandria Engineering Journal, Vol. 51, No. 1, 2012, pp. 11-18. http://dx.doi.org/10.1016/j.aej.2012.07.002

[7] N. Oztürk and T. E. Bektaş, "Nitrate Removal from Aqueous Solution by Adsorption onto Various Materials," Journal of Hazardous Materials, Vol. 112, No. 1-2, 2004, pp. 155-162.

http://dx.doi.org/10.1016/j.jhazmat.2004.05.001

[8] A. Azzouz, E. Assaad, A.-V. Ursu, T. Sajin, D. Nistor and R. Roy, "Carbon Dioxide Retention over Montmorillonite-Dendrimer Materials," Applied Clay Science, Vol. 48, No. 1-2, 2010, pp. 133-137. http://dx.doi.org/10.1016/j.clay.2009.11.021

[9] C. R. Reddy, Y. S. Bhat, G. Nagendrappa and B. S. Jai Prakash, "Brönsted and Lewis Acidity of Modified Montmorillonite Clay Catalysts Determined by FT-IR Spectroscopy," Catalysis Today, Vol. 141, No. 1-2, 2009, pp. 157-160. http://dx.doi.org/10.1016/j.cattod.2008.04.004

[10] H. Cheng, Q. Liu, J. Yang, S. Ma and R. L. Frost, "The Thermal Behavior of Kaolinite Intercalation ComplexesA Review," Thermochimica Acta, Vol. 545, 2012, pp. 113. http://dx.doi.org/10.1016/j.cattod.2008.04.004

[11] T. Shichi and K. Takagi, "Clay Minerals as Photochemical Reaction Fields," Journal of Photochemistry and Photobiology C: Photochemistry Reviews, Vol. 1, No. 2, 2000, pp. 113-130. http://dx.doi.org/10.1016/S1389-5567(00)00008-3

[12] H. He, Q. Tao, J. Zhu, P. Yuan, W. Shen and S. Yang, "Silylation of Clay Mineral Surfaces," Applied Clay Science, Vol. 71, 2013, pp. 15-20. http://dx.doi.org/10.1016/j.clay.2012.09.028

[13] E. Eren, "Removal of Copper Ions by Modified Unye Clay, Turkey," Journal of Hazardous Materials, Vol. 159, No. 2-3, 2008, pp. 235-244. http://dx.doi.org/10.1016/j.jhazmat.2008.02.035

[14] Z. Qian, G. Hu, S. Zhang and M. Yang, "Preparation and Characterization of Montmorillonite-Silica Nanocomposites: A Sol-Gel Approach to Modifying Clay Surfaces," Physica B: Condensed Matter, Vol. 403, No. 18, 2008, pp. 3231-3238. http://dx.doi.org/10.1016/j.physb.2008.04.008

[15] F. Hussin, M. K. Aroua and W. M. A. W. Daud, "Textural Characteristics, Surface Chemistry and Activation of Bleaching Earth: A Review," Chemical Engineering Journal, Vol. 170, No. 1, 2011, pp. 90-106. http://dx.doi.org/10.1016/j.cej.2011.03.065

[16] V. A. Bell, V. R. Citro and G. A. L. D. Hodge, "Effect of Pellet Pressing on the Infrared Spectrum of Kaolinite," Clays and Clay Minerals, Vol. 39, No. 3, 1991, pp. 290292. http://dx.doi.org/10.1346/CCMN.1991.0390309

[17] J. Madejova and P. Komadel, "Baseline Studies of the Clay Minerals Society Source Clays: Infrared Methods," Clays and Clay Minerals, Vol. 49, No. 5, 2001, pp. 410432. http://dx.doi.org/10.1346/CCMN.2001.0490508

[18] G. Murali Krishna, M. Muthukumaran, B. Krshnamoorthy and A. Nishat, "A Critical Review on Fundamental and Pharmaceutical Analysis of FTIR Spectroscopy," International Journal of Pharmacy, Vol. 3, No. 2, 2013, pp.
396-406.

[19] S. Yariv, "Thermo-IR-Spectroscopy Analysis of the Interactions between Organic Pollutants and Clay Minerals," Thermochimica Acta, Vol. 274, 1996, pp. 1-35.

[20] W. J. Brian, B. Jörg, D. Karl and P. Bruno, "Practical Considerations of the Ir Attenuated-Total-Reflection (ir-ATR) Technique for Electrochemical Investigations," Electrochimica Acta, Vol. 37, No. 12, 1992, pp. 2321-2329.

[21] M. Elena Ramos and F. Javier Huertas, "Adsorption of Glycine on Montmorillonite in Aqueous Solutions," Applied Clay Science, Vol. 80-81, 2013, pp. 10-17. http://dx.doi.org/10.1016/j.clay.2013.05.007

[22] R. L. Frost and E. Mendelovici, "Modification of Fibrous Silicates Surfaces with Organic Derivatives: An Infrared Spectroscopic Study," Journal of Colloid and Interface Science, Vol. 294, No. 1, 2006, pp. 47-52. http://dx.doi.org/10.1016/j.jcis.2005.07.014

[23] S. Shoval, S. Yariv, K. Michaelian, I. Lapides, M. Boudeuille and G. Panczer, "A Fifth OH-Stretching Band in IR Spectra of Kaolinites," Journal of Colloid and Interface Science, Vol. 212, No. 2, 1999, pp. 523-529. http://dx.doi.org/10.1006/jcis.1998.6055

[24] G. Sposito, "Infrared Spectroscopic Study of Adsorbed Water on Reduced-Charge Na/Li-Montmorillonites," Clays and Clay Minerals, Vol. 31, No. 1, 1983, pp. 9-16. http://dx.doi.org/10.1346/CCMN.1983.0310102

[25] S. Korichi, A. Elias and A. Mefti, "Characterization of Smectite after Acid Activation with Microwave Irradiation," Applied Clay Science, Vol. 42, No. 3-4, 2009, pp. 432-438. http://dx.doi.org/10.1016/j.clay.2008.04.014

[26] J. Murakami, "Synthesis of Kaolinite-Organic Nanohybrids with Butanediols," Solid State Ionics, Vol. 172, No. 1-4, 2004, pp. 279-282. http://dx.doi.org/10.1016/j.ssi.2004.02.048

[27] P. M. Amarasinghe, K. S. Katti and D. R. Katti, "Nature of Organic Fluid-Montmorillonite Interactions: An FTIR Spectroscopic Study," Journal of Colloid and Interface Science, Vol. 337, No. 1, 2009, pp. 97-105. http://dx.doi.org/10.1016/j.jcis.2009.05.011

[28] L. Jankovic, "Metal Cation-Exchanged Montmorillonite Catalyzed Protection of Aromatic Aldehydes with $\mathrm{Ac}_{2} \mathrm{O}$," Journal of Catalysis, Vol. 218, No. 1, 2003, pp. 227-233. http://dx.doi.org/10.1016/j.cej.2011.03.065

[29] G. Y. Zhang and D. Peak, "Studies of Cd(II)-Sulfate Interactions at the Goethite-Water Interface by Atr-Ftir Spectroscopy," Geochimica Et Cosmochimica Acta, Vol. 71, No. 9, 2007, pp. 2158-2169. http://dx.doi.org/10.1016/j.gca.2006.12.020

[30] Y. Brechbühl, I. Christl, E. J. Elzinga and R. Kretzschmar, "Competitive Sorption of Carbonate and Arsenic to Hematite: Combined ATR-FTIR and Batch Experiments," Journal of Colloid and Interface Science, Vol. 377, No. 1, 2012, pp. 313-321. http://dx.doi.org/10.1016/j.jcis.2012.03.025

[31] K. Morimoto, S. Anraku, J. Hoshino, T. Yoneda and T. Sato, "Surface Complexation Reactions of Inorganic Anions on Hydrotalcite-Like Compounds," Journal of Colloid and Interface Science, Vol. 384, No. 1, 2012, pp. 99-104. http://dx.doi.org/10.1016/j.jcis.2012.06.072 
[32] K. P. Nicolini, C. R. B. Fukamachi, F. Wypych and A. S. Mangrich, "Dehydrated Halloysite Intercalated Mechanochemically with Urea: Thermal Behavior and Structural Aspects," Journal of Colloid and Interface Science, Vol. 338, No. 2, 2009, pp. 474-479. http://dx.doi.org/10.1016/j.jcis.2009.06.058

[33] A. Spence and B. P. Kelleher, "FT-IR Spectroscopic Analysis of Kaolinite-Microbial Interactions," Vibrational Spectroscopy, Vol. 61, 2012, pp. 151-155. http://dx.doi.org/10.1016/j.vibspec.2012.02.019

[34] H. Long, P. Wu and N. Zhu, "Evaluation of $\mathrm{Cs}^{+}$Removal from Aqueous Solution by Adsorption on EthylamineModified Montmorillonite," Chemical Engineering Journal, Vol. 225, 2013, pp. 237-244. http://dx.doi.org/10.1016/j.cej.2013.03.088

[35] V. Matějka, M. Šupová, V. Klemm, D. Rafaja, M. Valášková, J. Tokarský, et al., "Vermiculite Interlayer as a Reactor for CdS Ultrafine Particles Preparation," Microporous and Mesoporous Materials, Vol. 129, No. 1-2, 2010, pp. 118-125.

http://dx.doi.org/10.1016/j.micromeso.2009.09.006

[36] P.-H. Chang, Z. Li, J.-S. Jean, W.-T. Jiang, C.-J. Wang and K.-H. Lin, "Adsorption of Tetracycline on 2:1 Layered Non-Swelling Clay Mineral Illite," Applied Clay Science, Vol. 67-68, 2012, pp. 158-163. http://dx.doi.org/10.1016/j.clay.2011.11.004

[37] H. Tan, W. Skinner and J. Addai-Mensah, "Leaching Behaviour of Low and High Fe-Substituted Chlorite Clay
Minerals at Low pH," Hydrometallurgy, Vol. 125-126, 2012, pp. 100-108.

http://dx.doi.org/10.1016/j.hydromet.2012.05.015

[38] Y. Deng, J. B. Dixon, G. N. White, R. H. Loeppert and A. S. R. Juo, "Bonding between Polyacrylamide and Smectite," Colloids and Surfaces A: Physicochemical and Engineering Aspects, Vol. 281, No. 1-3, 2006, pp. 82-91. http://dx.doi.org/10.1016/j.colsurfa.2006.02.030

[39] C. Bisio, G. Gatti, E. Boccaleri, L. Marchese, G. B. Superti, H. O. Pastore and M. Thommes, "Understanding Physico-Chemical Properties of Saponite Synthetic Clays," Microporous and Mesoporous Materials, Vol. 107, No. 1-2, 2008, pp. 90-101.

http://dx.doi.org/10.1016/j.micromeso.2007.05.038

[40] S. Akyuz, T. Akyuz and E. Akalin, "Adsorption of Isoniazid onto Sepiolite-Palygorskite Group of Clays: An IR Study, Spectrochimica Acta. Part A," Molecular and Biomolecular Spectroscopy, Vol. 75, No. 4, 2010, pp. 1304 1307. http://dx.doi.org/10.1016/j.saa.2009.12.069

[41] M. Zamama and M. Knidiri, "IR Study of Dickite-Formamide Intercalate, $\mathrm{Al}_{2} \mathrm{Si}_{2} \mathrm{O}_{5}(\mathrm{OH})_{4}-\mathrm{H}_{2} \mathrm{NCOH}$," Spectrochimica Acta. Part A, Molecular and Biomolecular Spectroscopy, Vol. 56, No. 6, 2000, pp. 1139-1147. http://dx.doi.org/10.1016/S1386-1425(99)00212-7

[42] B. Feng, Q. Feng and Y. Lu, "The Effect of Lizardite Surface Characteristics on Pyrite Flotation," Applied Surface Science, Vol. 259, 2012, pp. 153-158. http://dx.doi.org/10.1016/j.apsusc. 2012.07 .010 